\title{
APRESENTAÇÃO
}

\section{Legitimação social e práticas de linguagem}

Anna Christina Bentes ${ }^{l}$

Suzi Frankl Sperber ${ }^{l}$

A

proposta desse número do Cadernos CEDES é a de reunir textos de pesquisadores ${ }^{1}$ de diferentes campos dos estudos da aplicados - de diferentes universidades brasileiras e de uma universidade norte-americana.

Composto por sete artigos, o dossiê traz um caleidoscópio de objetos e de perspectivas em torno do tema "Legitimaçáo social, gêneros do discurso e práticas de linguagem" e tem como principal objetivo a sistematização de reflexóes e de análises com base em distintas perspectivas teóricas e com aparatos metodológicos diferenciados sobre as relaçôes entre práticas de linguagem e a questáo da legitimaçáo social. A publicaçáo permitirá que os leitores tenham uma visão bastante diversificada, aprofundada e aplicada da natureza dos processos de legitimação, sejam eles vistos como processos resultantes da internalizaçáo/mimetizaçáo de todo um sistema de dominaçấo, sejam como procedimentos advindos de lutas por (des)legitimaçáo empreendidas pelos agentes no interior dos campos sociais.

A ordem dos textos que integram este volume pode ser compreendida como um percurso provocativo que abarca inúmeros

\footnotetext{
${ }^{1}$ Universidade Estadual de Campinas - Campinas (SP), Brasil. E-mails: annafapesp@hotmail.com,sperbersuzi@hotmail.com DOI: 10.1590/CC0101-32622018183525
} 
objetos, temáticas e pontos de vista. Um percurso que visita os diferentes campos sociais: o das mídias digitais na intersecção com o campo político, o das patologias, o literário e o educacional (ensino superior e básico). Começando pelos âmbitos midiático e político, o primeiro artigo proporciona um olhar sobre outra sociedade, a norte-americana, no contexto de exercício dos primeiros meses de mandato do presidente dos Estados Unidos Donald Trump. Na visão das autoras Dale Koike e Anna Christina Bentes, o atual presidente busca legitimar, por meio de suas tweetstorms, uma agenda antirreflexiva, combatida pela grande mídia norte-americana e por outros campos sociais, o que revela que os processos de legitimação se constituem em lutas contínuas por conquista de reconhecimento de determinadas agendas sociais, especialmente quando estão em jogo atores sociais já investidos de grande autoridade, status e poder, como as elites norte-americanas - ou, como é o caso do presidente, que prefere a conquista do reconhecimento pela imposição de seu espaço e voz.

O texto seguinte, de Edwiges Morato, que toma como objeto de reflexão o campo das patologias, compartilha com o anterior o pressuposto de que a legitimação de uma prática por parte de determinados grupos é forjada nas lutas sociais, porque, segundo a autora, "a legitimidade não é apenas imposição e subordinação, mas conquista e mudança”. Dessa forma, legitimação é, para ela, um conceito relacional no qual es- tão em jogo "estruturas ou esquemas de expectativa, representação de experiências de vida em sociedade, negociação, tomada de consciência, reflexividade". A autora trabalha a relação entre processos de legitimação, estigmatização e injustiça social quando do comprometimento de capa- cidades comunicativas interacionais, sociocognitivas e profissionais nos contextos de afasia e doença de Alzheimer. Se o primeiro artigo enfoca lutas por (des) legitimação de certas práticas sociais no imbricamento dos campos midiático e político, o segundo tem por objetivo observar que

o fenômeno da (des)legitimação comunicativa e interacional de indivíduos afásicos ou com diagnóstico de doença de Alzheimer tem uma natureza polissêmica, polimórfica e multimodal, passível de ser observada, 
reconhecida e coletivizada por meio de normas que constituem e presidem os regimes simbólicos dos muitos campos sociais.

O terceiro e o quarto textos tratam do tema no campo literário. O trabalho de Sandra Luna traça um percurso que mostra a importância do status social do herói na constituição de seu ethos, levando em conta especialmente um breve histórico do teatro. Ao afirmar que "a literatura nasce de um impulso para a idealização, que não se afasta de um impulso para a elitização", a autora associa a emergência da mimésis literária à elaboração de heróis que assumem as vestimentas das elites sociais: "É possível reconstituir a história da literatura examinando como as formas artísticas, em diferentes tempos e espaços, representam os seres humanos em suas vestimentas sociais para engendrar significaçóes estéticas, éticas, políticas”. Ela busca esclarecer a complexidade da elaboração da legitimação social das personagens teatrais, num delicioso passeio desde o contexto da Antiguidade greco-romana clássica, passando pelo teatro renascentista, chegando até a criação dos dramas modernos e pós- -modernos, apontando como, em cada um desses contextos históricos, o status social das personagens é ligado a mais ou menos dignidade el ou virtude ética. Como a homologia entre essas qualidades e as clas- ses altas não é mantida, a autora deixa entrever que as mudanças, nessa correlação, são historicamente necessárias e esteticamente instigantes por poderem subverter "o sentido de legitimação social”, desestabilizando antigas convenções.

O quarto texto, de Luís Fernando Prado Telles, enfoca a questão da legitimação social promovida pelas práticas de escrita literária, considerando dois modos de legitimação da literatura: certas instâncias de sua legitimação/autenticação e o seu próprio lugar discursivo de prestígio. $\mathrm{O}$ autor enfatiza que essas duas formas de pensar o processo de legitimação da literatura, apesar de distintas, podem ser entendidas como imbricadas, uma vez que a literatura não possuiria valor em essência. $\mathrm{O}$ que a constituiria como um lugar de prestígio seria o processo anterior de legitimação efetivado por outras instâncias, necessariamente comunitárias e locais, já 
que não há uma única instância de legitimação da escrita literária, mas múltiplas, complexas e relativas entre si, e também existe uma triangulação entre as esferas das literaturas ditas erudita, popular e de mercado. Segundo Telles, esses mesmos processos locais e comunitários de legitimação estão associados à consolidação de um "nome de autor", que individualiza a prática literária e possibilita a construção do efeito de uma entidade anterior e exterior ao texto. No entanto, para ele, "determinada prática literária ou determinado 'nome de autor' serão legitimados a depender do grau de pertencimento a determinados valores comunitários". Por fim, são destacados os complexos processos locais e comunitários de legitimação social que operam nas redes sociais em contextos digitais e que acabam por reforçar lógicas de legitimação guiadas pela fácil aceitação e pela capacidade de gerar renda em larga escala.

Os textos seguintes inscrevem-se no campo educacional, mas com temas e objetos diferentes. O quinto artigo preocupa-se com os processos de legitimação social envolvidos na elaboração de políticas de internacionalização de uma instituição de ensino superior. Considerando o período de 2009 a 2016, em que houve grande incentivo, por parte do go- verno federal, à internacionalização das universidades, Inês Signorini teve por objetivo, em seu texto, "descrever estratégias de legitimação de polí- ticas científicas voltadas para a internacionalização de uma universidade pública paulista”. Trabalhando com um corpus de referência constituído de documentos institucionais (locais e transnacionais) sobre o tema, editais locais para financiamento de pesquisa e chamadas para cursos e seminários voltados para a inovação e a internacionalização da pesquisa, a autora pretendeu mostrar que "tais estratégias são também estratégias de legitimação da gestão e de reprodução do poder institucional e, consequentemente, de reprodução da hierarquização de atores e discursos dentro da instituição".

Para tanto, a autora inicia seu escrito com uma discussão acerca do próprio conceito de internacionalização, concebido como tendo caráter dinâmico, variado, complexo e competitivo, "o que torna relevante a premissa de que, no campo social, a legitimidade é sempre objeto de disputa e discussão, ou seja, não é um bem permanente ou estável”. Em seguida, discute “a importância do ran- 
queamento, sobretudo os internacionais, na formulação e legitimação de políticas locais de estímulo ou indução à inovação, à pesquisa e à cooperação internacional”. Como principal resultado do trabalho, a autora afirma:

No que se refere às hierarquias no campo institucional, em função de critérios e normas próprias dos ranqueamentos tomados como referência, e tidos como imparciais e objetivos, manteve-se a posição historicamente marginal das ciências humanas, particularmente dos estudos da linguagem nos processos de definição e implementação das políticas locais de internacionalização, inclusive das políticas linguísticas.

Nesse sentido, o texto ressalta o caráter político-discursivo dos processos de legitimação, dado que estes consistem na "atribuição ou reconhecimento da legitimidade e, portanto, da aceitabilidade de determinados atores, açôes e relaçôes sociais num dado contexto normativo".

Os outros dois trabalhos são voltados para processos de legitimação envolvendo objetos e práticas de ensino na educação básica. O sexto texto, de Sandoval Nonato Gomes-Santos, busca trazer elementos para a discussão sobre processos de legitimação pelos quais se estabelece certo estatuto para a linguagem oral como objeto de ensino na prática escolar. Para tanto, no primeiro momento, o autor, com base no conceito de forma escolar desenvolvido na reflexão do sociólogo da educação francês Bernard Lahire, discute como a linguagem oral, tal qual objeto de ensino, não se presta muito bem à produção de disposiçôes nos indivíduos para um determina- do tipo de ação sobre o saber: ações de análise, de comparação, de decomposição, de classificação, de decodificação, na base das quais se encontra o reforço de uma atitude taxonômica fundada, entre outros aspectos, em concepçóes racionalistas do raciocínio.

Nessa perspectiva, a forma escolar seria constituída da "denegação das formas de produção e consumo de saberes que en- 
contram na experiência vivida e na presença material desses saberes sua condiçáo de possibilidade". No segundo momento, o autor retoma aspectos gerais do percurso de constituição do ensino de língua portuguesa na escola brasileira em termos de currículos e programas de ensino e dos materiais didáticos propostos, assinalando certos traços dos processos de legitima- ção da linguagem oral. Ao final dessa parte, ele enuncia um dos principais desafios para a legitimaçẫo da linguagem oral na escola: do ponto de vista do saber escolar (conteúdos ou objetos de ensino), a opçáo pela língua em uso como objeto de saber, de um saber de natureza constitutivamente praxeológica, incluindo-se aqui a construção de projetos didáticos voltados para o cordel, o texto teatral, a cançáo po- pular, além de gêneros orais formais e públicos, como debate e exposição oral.

Por fim, o autor analisa uma experiência de ensino do gênero debate com alunos do ensino médio de uma escola federal do Norte do país. Fundamentado na observação de "um ponto de fuga na aparente linearidade e homogeneidade do percurso didático construí- do", avalia gestos que produzem tensóes em relação a "uma apropriaçáo considerada adequada dos saberes e dos modos de fazer legitimados e instanciados no ritual de produção dos gêneros textuais na escola”. Em suas consideraçôes finais, Gomes-Santos ainda póe em cena as açóes políticas derivadas das ocupaçóes das escolas paulistas ocorridas em 2016, mostrando como tais ocupações, por meio de suas agendas temáticas, da apropriação adequada de recursos multissemióticos na produção discursiva dos estudantes, conferem centralidade à linguagem oral, ao protagonismo estudantil e ao diálogo vivo entre os diferentes atores sociais que integram a instituição escolar.

O último artigo do volume é o de Márcia Mendonça, que discute aspectos da seleção e legitimação de gêneros do discurso tomados como objeto de ensino na implementação de projetos didáticos de língua portuguesa. Com base em entrevistas semiestruturadas com bolsistas do Programa Institucional de Bolsas de Iniciação à Docência (PIBID) do curso de Letras, a autora busca compreender as percepçóes dos professores em formação quanto ao papel e à (ir)relevância dos gêneros do discurso como objeto de ensino nos 
projetos didáticos. Acreditando que uma melhor compreensão dessas percepçóes pode contribuir para problematizar tanto o trabalho com os gêneros na escola como os processos formativos que tomam corpo nas universidades e no âmbito de programas como o PIBID, a autora pensa, no primeiro momento, em como se dá a apropriação dos gêneros no contexto das práticas escolares, tendo em conta que eles se constituem como parte do capital cultural valorizado/legitimado, em maior ou menor grau, em documentos curriculares e em discursos de agentes educacionais. Após fazer uma breve contextualização das entrevistas com os bolsitas, a autora passa a descrever como os estudantes percebem as relevâncias e pertinências dos gêneros do discurso nos projetos de ensino por eles desenvolvidos. As conclusóes do artigo apontam para o fato de que, ao lado de critérios mais legitimados pela instância universitária de formação (relevância fundada em teorias consolidadas) ou pela instituição escolar (previsão no currículo escolar, adequação ao perfil da turma e da escola), outros fatores influenciaram a escolha dos gêneros do discurso nos projetos. [...] Assim, mais que saberes de formação profissional, disciplinares ou curriculares, são mobilizados/(re)elaborados saberes experienciais acerca de quais gêneros selecionar, com quais objetivos e por que razóes. Os saberes experienciais acerca desse processo de seleção dos gêneros tomados como objetos de ensino resultam da atividade laboral dos professores, dado que são por eles produzidos na vivência de situaçóes específicas ligadas ao espaço escolar e às relaçóes estabelecidas com os demais membros da comunidade escolar.

Acreditamos que o volume com tal configuração descrita pode contribuir para a melhor compreensão de como diferentes pesquisadores do campo de estudos da linguagem buscaram conferir a seus objetos e temas de pesquisa um tratamento de natureza inter/transdisciplinar, considerando o complexo conceito de legitimação social. Oxalá esses exercícios analíticos possam repercutir no campo da educação e inspirem os leitores a perceber esse conceito nas suas múltiplas dimensóes e na sua estratégica força reflexiva. 


\section{REFERÊNCIA}

ALBUQUERQUE, C.P. Legitimidade e reconhecimento da prática de serviço social. Abordagem construtivista. Serv. Soc. Rev., n. 13 (2), p. 104-118, 2011.

\section{NOTA}

1 Os pesquisadores brasileiros participaram do IV Colóquio do Centro de Pesquisas Margens: Legitimação Social, Gêneros do Discurso e Práticas de Linguagem, realizado no Instituto de Estudos da Linguagem, na Universidade Estadual de Campinas, em maio de 2016.

Recebido em 02 de agosto de 2017.

Aprovado em 23 de março de 2018. 